\title{
The Effect of Gum Arabic on the Nano / Microstructure and Optical Properties of Precipitated ZnO
}

\author{
Željka Petrović, ${ }^{1}$ Mira Ristić, ${ }^{1, *}$ Svetozar Musić, ${ }^{1,2}$ Martin Fabián ${ }^{3}$
}

\author{
1 Division of Materials Chemistry, Ruđer Bošković Institute, Bijenička cesta 54, HR-10002 Zagreb, Croatia \\ 2 Croatian Academy of Sciences and Arts, Zrinski trg 11, HR-10002 Zagreb, Croatia \\ 3 Institute of Geotechnics, Slovak Academy of Sciences, SK-04001 Košice, Slovakia \\ * Corresponding author's e-mail address: ristic@irb.hr
}

RECEIVED: March 10, 2017 * REVISED: May 8, 2017 * ACCEPTED: May 8, 2017

Abstract: The development of the nano/microstructure of $\mathrm{ZnO}$ particles precipitated from zinc acetylacetonate showed dependence on the presence of gum arabic. In the absence of gum arabic in near-neutral pH range $\mathrm{ZnO}$ rods, some of them hollow, precipitated, whereas in alkaline $\left(\mathrm{NH}_{4} \mathrm{OH}\right)$ medium the multipods (stars) were obtained. A strong effect of gum arabic was noticed both in the near-neutral $\mathrm{pH}$ range and in alkaline $\left(\mathrm{NH}_{4} \mathrm{OH}\right)$ medium. In both cases $\mathrm{ZnO}$ particles consisted of $1 \mathrm{D}$ subunits. The FT-IR spectra of $\mathrm{ZnO}$ particles precipitated in the presence of gum arabic showed the IR bands due to the residual content of this biopolymer. Gum arabic formed the corona on ZnO particles and played a key role in the precipitation process from nucleation to the final ZnO product. UV/Vis spectra were also recorded. The PL spectra of ZnO powders dispersed in pure ethanol were very similar. In the presence of ethanol characteristic peaks in the blue emission region were diminishing, thus softening the intrinsic defects responsible for this emission. It was assumed that this effect was due to the covering of oxygen vacancies $\left(V_{0}\right)$ at the interface $\mathrm{ZnO} / \mathrm{C}_{2} \mathrm{H}_{5} \mathrm{OH}$ with the oxygen atoms present in ethanol.

Keywords: $\mathrm{ZnO}$, gum arabic, nano/microstructure, optical properties.

\section{INTRODUCTION}

$\mathbf{Z}$ INC oxide $(\mathrm{ZnO})$ is a semiconductor characterized by a wide direct band gap of $3.37 \mathrm{eV}$ and a large exciton binding energy of $\sim 60 \mathrm{meV}$. In the last 15 years $\mathrm{ZnO}$ has received considerable attention of researchers as documented in numerous publications about the synthesis and properties of $\mathrm{ZnO}$ particles. The specific properties of ZnO particles (crystallites) strongly depend on their size and nano/microstructure. The size and nano/microstructure of ZnO particles (crystallites) can be tuned by changing the experimental conditions (parameters) of the synthesis route chosen. In this sense chemical conditions such as the type of Zn-salt or alkali, solvent and the presence of different organic ions and molecules play an important role in the formation of $\mathrm{ZnO}$. These organic ions and molecules can be roughly divided into three groups. In the first group are small synthetic organic ions. For example, a strong effect of citrate complexing agent on the formation of various $\mathrm{ZnO}$ nano/microstructures has been noticed. ${ }^{[1-3]}$ The synthetic surface active agents are the second group of organic compounds which also influence the size, geometrical shape or aggregation of $\mathrm{ZnO}$ particles. ${ }^{[4-11]}$ In the third group are natural organic compounds, for example biopolymers. ${ }^{[12-17]}$ Spherical $\mathrm{ZnO}$ nanoparticles of narrow size distribution were synthesized in the presence of carboxylic curdlan (Cc), a versitale $\beta$-1,3-polyglucuronic acid derivative. The obtained Cc-ZnO nanoparticles showed a good ability of binding proteins. ${ }^{[18]}$

Recently, we have noticed a very strong effect of sodium polyanethol sulfonate (SPAS) on the formation and properties of $\mathrm{ZnO}$ particles under the hydrothermal treatment of zinc acetylacetonate $\left(\mathrm{Zn}(\mathrm{acac})_{2}\right)$ in aqueous medium. ${ }^{[19]}$ Two types of hollow $\mathrm{ZnO}$ particles were

(c) Br $\mathbf{B Y}$ This work is licensed under a Creative Commons Attribution 4.0 International License. 
obtained and this effect was explained with two different mechanisms of the formation of these $\mathrm{ZnO}$ particles.

$\mathrm{Zn}(\mathrm{acac})_{2}$ easily undergoes rapid hydrolysis in contact with $\mathrm{H}_{2} \mathrm{O}$ and this reaction can be utilized to produce $\mathrm{ZnO}$ particles. ${ }^{[20]} \mathrm{Zn}(\mathrm{acac})_{2}$ was also used as a starting chemical in different synthesis conditions to produce $\mathrm{ZnO}$ nanoparticles. [21-23]

In continue of our previous work ${ }^{[19]}$ on the effect of synthetic polymer sodium polyanethol sulfonate, we have investigated the effect of natural biopolymer gum arabic (GA) on the precipitation from zinc acetylacetonate in the aqueous medium. Special focus was given to the monitoring the changes in nano/microstructural and optical properties of $\mathrm{ZnO}$ particles precipitated in the presence of gum arabic in relation to reference $\mathrm{ZnO}$ particles.

Gum arabic is a natural biopolymer from the acacia tree with complex chemical composition containing a high fraction of polysaccharides ( 97\%; D-galactose, L-arabinose, as well as L-rhamnose and D-glucuronic acid). A smaller amount $(<3 \%)$ of glycoproteins is also present. In addition to that, small or trace amounts of inorganics such as $\mathrm{Ca}, \mathrm{K}$, $\mathrm{Mg}, \mathrm{Ca}, \mathrm{Fe}, \mathrm{Mn}$ or $\mathrm{Zn}$ can be found in gum arabic. The actual presence of organics and inorganics in gum arabic depends on the geographic location of the acacia tree.

\section{EXPERIMENTAL}

\section{Preparation of Samples}

Experimental conditions for the preparation of reference $(Z$ samples) and those prepared in the presence of gum arabic (ZG samples) are given in Table 1. Reference samples $\mathrm{Z1}$ to $\mathrm{Z3}$ were prepared by adding $0.4 \mathrm{~g} \mathrm{Zn}(\mathrm{acac})_{2} \cdot \mathrm{H}_{2} \mathrm{O}$ to $\mathrm{H}_{2} \mathrm{O}$, whereas reference samples $\mathrm{Z} 4$ to $\mathrm{Z} 6$ were prepared by adding the same amount of $\mathrm{Zn}(\mathrm{acac})_{2} \cdot \mathrm{H}_{2} \mathrm{O}$ to the aqueous solution of $\mathrm{NH}_{4} \mathrm{OH}$. Thus formed milky suspension was homogenized in an ultrasonic bath for $15 \mathrm{~min}$, then autoclaved in a preheated oven at $160^{\circ} \mathrm{C}$ for 2,4 or $24 \mathrm{~h}$. When the required time elapsed the autoclave was left to cool at room temperature (RT). Then the precipitate was separated from the mother liquor by centrifugation and subsequently washed with $\mathrm{H}_{2} \mathrm{O}$ and $\mathrm{C}_{2} \mathrm{H}_{5} \mathrm{OH}$. The isolated precipitates were dried in vacuum at $\mathrm{RT}$.

The procedure for the preparation of ZG samples was almost the same, but a proper amount of gum arabic was first added to $\mathrm{H}_{2} \mathrm{O}$ or the aqueous solution of $\mathrm{NH}_{4} \mathrm{OH}$ and then ultrasonicated for 5 min before adding $\mathrm{Zn}(\mathrm{acac})_{2} \cdot \mathrm{H}_{2} \mathrm{O}$.

A teflon-lined non-stirred vessel (autoclave) manufactured by Parr Instrument Company (model 4744) was used. The autoclaving vessel was heated in a DX300 gravity oven (Yamoto) with uniformity $\pm 1.9^{\circ} \mathrm{C}$ at $100^{\circ} \mathrm{C}$ or $\pm 3{ }^{\circ} \mathrm{C}$ at $200{ }^{\circ} \mathrm{C}$. A Labogene centrifuge ScanSpeed $2236 \mathrm{R}$ was also used.

\section{Characterization of Samples}

XRD patterns were recorded at $20^{\circ} \mathrm{C}$ in the $2 \theta$ range from 20 to $70^{\circ}$ using an APD 2000 diffractometer manufactured by ItalStructures (GNR-Analytical Instruments Group, Italy). The CuK $\alpha$ wavelength $(\lambda=0.15406 \mathrm{~nm}), 40 \mathrm{kV}$ high voltage and $30 \mathrm{~mA}$ current were applied.

The shape and size of particles were inspected with a thermal field emission scanning electron microscope (FESEM, model JSM 7000F, manufactured by Jeol Ltd.).

A Fourier transform infrared (FT-IR) spectrometer (model ALPHA) manufactured by Bruker was used.

The ultraviolet-visible (UV/Vis) spectra were recorded with a Shimadzu UV/Vis/NIR spectrometer (model UV-3600) connected to an integrating sphere.

The photoluminescence (PL) spectra were recorded with PC1 (ISS, USA) spectrofluorometer using a $300 \mathrm{~W}$ Xe lamp as an excitation source with wavelength $\lambda=325 \mathrm{~nm}$. Samples were measured in the form of powder or ethanolic dispersion (approximately $2.5 \times 10^{-5} \mathrm{~mol} \mathrm{dm}^{-3}$ of powder was dispersed by ultrasonification in pure ethanol).

\section{RESULTS AND DISCUSSION}

\section{XRD}

The XRD results revealed that all samples prepared (Table 1) were crystalline and can be assigned to the hexagonal $\mathrm{ZnO}$ phase (würtzite-type crystal structure, space group: $P 6_{3} m c$ (186), $a=0.3249 \mathrm{~nm}, c=0.5206 \mathrm{~nm}$, JCPDS card No. 36-1451). The XRD patterns of selected samples are shown in Figures 1 and 2. A small difference in the relative intensities of diffraction lines (100), (002) and (101) are noticed. Hexagonal $\mathrm{ZnO}$ crystals are characterized by specific properties. Two main properties of hexagonal $\mathrm{ZnO}$ are (a) tetrahedral coordination of zinc atoms resulting in a noncentral symmetric structure and (b) polar surfaces. The oppositely charged ions produce a positively charged $\mathrm{Zn}$-(0001) plane (top surface) and a negatively charged O- $(000 \overline{1})$ plane (bottom surface). As a result of these properties the normal dipole moment and spontaneous polarization appear along the $c$-axis. These specific physical properties of $\mathrm{ZnO}$ can be related to the formation of various nano/microstructures. This can be achieved by varying the route and conditions of $\mathrm{ZnO}$ synthesis.

Changes in ZnO crystallite size of the prepared samples were estimated using the well-known Scherrer formula,

$$
d=\frac{0.9 \lambda}{\beta \cos \Theta}
$$

where $d$ is the crystallite diameter, $\lambda$ is the $X$-ray 
Table 1. Experimental conditions for the preparation of samples $Z 1$ to $Z 6$ and $Z G 1$ to $Z G 12$ at $160{ }^{\circ} \mathrm{C}$.

\begin{tabular}{|c|c|c|c|c|c|}
\hline Sample & $\begin{array}{c}\mathrm{Zn}(\text { acac })_{2} \mathrm{H}_{2} \mathrm{O} \\
/ \mathrm{g}\end{array}$ & $\begin{array}{l}\mathrm{GA}^{(\mathrm{a})} \\
/ \mathrm{g}\end{array}$ & $\begin{array}{l}\mathrm{H}_{2} \mathrm{O} \\
/ \mathrm{mL} \\
\end{array}$ & $\begin{array}{c}25 \% \mathrm{NH}_{3}(\mathrm{aq}) \\
/ \mathrm{mL}\end{array}$ & $t / h$ \\
\hline $\mathrm{Z1}$ & 0.4 & & 40 & & 2 \\
\hline Z2 & 0.4 & & 40 & & 4 \\
\hline Z3 & 0.4 & & 40 & & 24 \\
\hline ZG1 & 0.4 & 0.02 & 40 & & 2 \\
\hline ZG2 & 0.4 & 0.02 & 40 & & 4 \\
\hline ZG3 & 0.4 & 0.02 & 40 & & 24 \\
\hline ZG4 & 0.4 & 0.04 & 40 & & 2 \\
\hline ZG5 & 0.4 & 0.04 & 40 & & 4 \\
\hline ZG6 & 0.4 & 0.04 & 40 & & 24 \\
\hline ZG7 & 0.4 & 0.1 & 40 & & 2 \\
\hline ZG8 & 0.4 & 0.1 & 40 & & 4 \\
\hline ZG9 & 0.4 & 0.1 & 40 & & 24 \\
\hline Z4 & 0.4 & & 35 & 5 & 2 \\
\hline $\mathrm{Z} 5$ & 0.4 & & 35 & 5 & 4 \\
\hline Z6 & 0.4 & & 35 & 5 & 24 \\
\hline ZG10 & 0.4 & 0.1 & 35 & 5 & 2 \\
\hline ZG11 & 0.4 & 0.1 & 35 & 5 & 4 \\
\hline ZG12 & 0.4 & 0.1 & 35 & 5 & 24 \\
\hline
\end{tabular}

(a) $\mathrm{GA}=$ gum arabic.

wavelength, $\theta$ is the Bragg angle and $\beta$ is the full width of the diffraction line at half the maximum intensity. The average crystallite sizes were estimated using the prominent diffraction lines (100), (002), (101), (110) and are given in Table 2. Reference samples Z1 to Z3 did not show significant changes in crystallite size between 2 and $24 \mathrm{~h}$ of autoclaving. A slight increase in crystallite size was noticed in order ZG1 to ZG9, i.e. in ZnO samples precipitated in the presence of increased amounts of GA. On the other hand, the crystallite sizes of samples ZG10 to ZG12 precipitated in alkaline medium showed smaller values in relation to reference samples Z4 to Z6.

\section{FE-SEM}

The characteristic FE-SEM images of $\mathrm{ZnO}$ particles are shown in Figures 3 and 4. Figure 3abc shows $\mathrm{ZnO}$ rods of micron size length, some of them are hollow. The precipitation of $\mathrm{ZnO}$ in the presence of gum arabic showed a very strong effect on the nano / microstructure of particles (Figure 3def). ZnO twins consisting of nanoparticles as subunits are well visible (Figure 3de) and this nano / microstructure is disappearing with prolonged time of autoclaving up to 24h. The precipitation of $\mathrm{ZnO}$ in the presence of $\mathrm{NH}_{4} \mathrm{OH}$ (reference samples) showed the formation of multipod
Table 2. Average crystallite dimensions of $\mathrm{ZnO}$ samples estimated by Scherrer method.

\begin{tabular}{cl}
\hline Sample & $d^{(\text {a) }} / \mathrm{nm}$ \\
\hline Z1 & $25 .(7)$ \\
Z2 & $24 .(9)$ \\
Z3 & $25 .(6)$ \\
ZG1 & $25 .(3)$ \\
ZG2 & $22 .(3)$ \\
ZG3 & $25 .(3)$ \\
ZG4 & $29 .(5)$ \\
ZG5 & $21 .(8)$ \\
ZG6 & $32 .(5)$ \\
ZG7 & $28 .(0)$ \\
ZG8 & $30 .(8)$ \\
ZG9 & $35 .(5)$ \\
Z4 & $33 .(6)$ \\
Z5 & $32 .(3)$ \\
Z6 & $35 .(6)$ \\
ZG10 & $20 .(8)$ \\
ZG11 & $22 .(0)$ \\
ZG12 & $32 .(0)$ \\
\hline
\end{tabular}

(a) Number in the parenthesis denotes the standard uncertainty of the less significant digit.

hexagonal particles (Figure 4abc). Phuruangrat et al. noticed the formation of $\mathrm{ZnO}$ particles in the form of hexagonal prisms and pyramids utilizing the reaction of hexamethylenetetramine (HMTA) in a microwave oven at $96{ }^{\circ} \mathrm{C} \cdot{ }^{[24]}$

The addition of gum arabic to reference $\mathrm{ZnO}$ samples Z4, Z5 and Z6 (Figure 4abc) showed a strong influence on the nano / microstructure of particles (Figure 4def). These particles (Figure 4de) consisted of nanorods as subunits. The width of $\mathrm{ZnO}$ subunits formed upon $24 \mathrm{~h}$ of autoclaving increased (Figure 4f) significantly. The increase in size of these $\mathrm{ZnO}$ subunits could be assigned to recrystallization via the solution.

Generally, the properties of $\mathrm{ZnO}$ can be greatly influenced if the precipitation process is conducted in the presence of natural compounds. For example, Jitianu and Goia precipitated $\mathrm{ZnO}$ particles of different sizes and shapes by slowly adding $\mathrm{Zn}\left(\mathrm{NO}_{3}\right)_{2}, \mathrm{ZnSO}_{4}$ or $\mathrm{Zn}\left(\mathrm{CH}_{3} \mathrm{COO}\right)_{2}$ salt solution with $\mathrm{NaOH}$ solution in parallel to the aqueous solution of gum arabic.[16] Tseng et al. prepared $\mathrm{ZnO}$ hierarchical mesocrystals by a biomimetic method using gelatin as a structure directing agent. ${ }^{[25]} \mathrm{ZnO}$ twin-crystals were produced when gelatin was replaced with gum arabic, while other experimental conditions remained the same. ${ }^{[26]}$ 


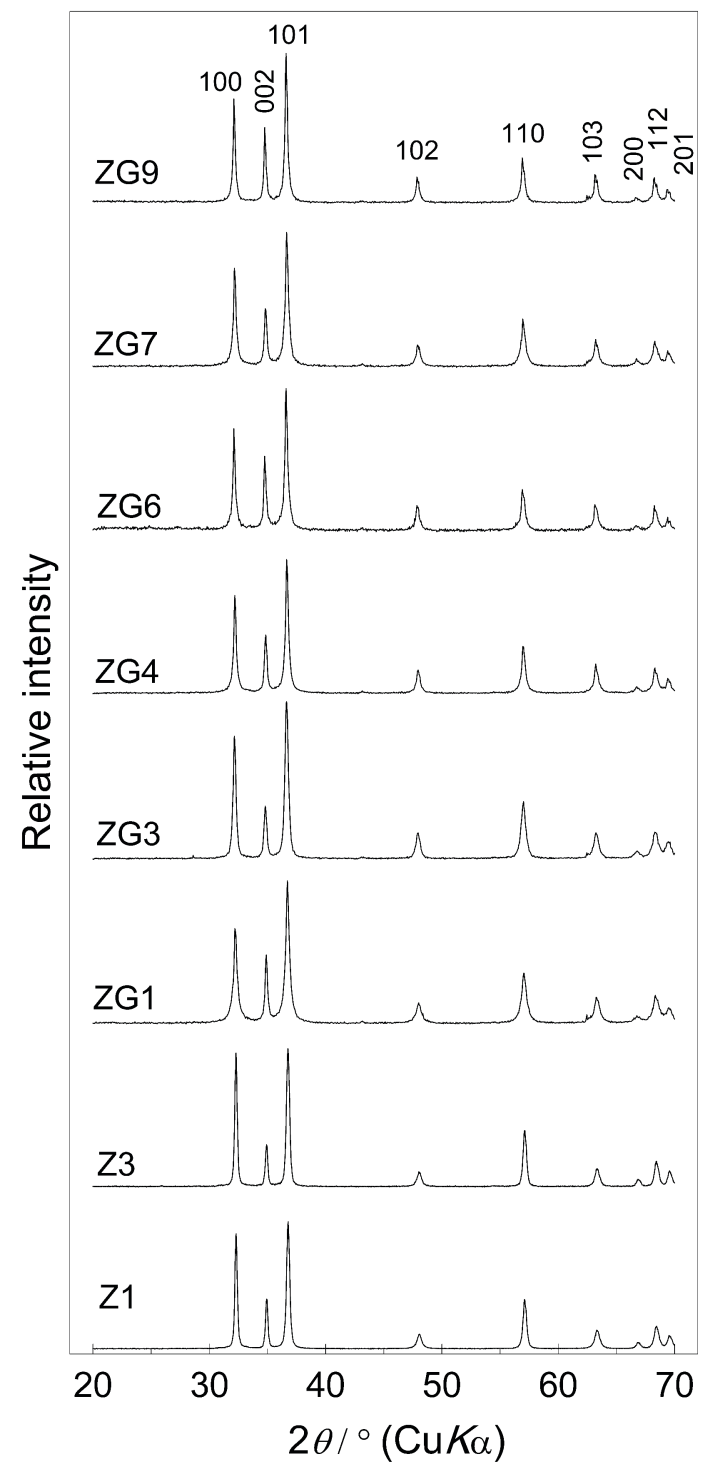

Figure 1. Selected XRD patterns of reference samples Z1, Z3 and samples ZG1, ZG3, ZG4, ZG6, ZG7 and ZG9 precipitated in the presence of gum arabic.

Different $\mathrm{ZnO}$ microstructures were obtained under hydrothermal conditions at $120^{\circ} \mathrm{C}$ for $2 \mathrm{~h}$ using zinc acetate, triethanolamine or saccharides (glucose, fructose, sucrose, dextran, starch or methylcellulose) as reactants. ${ }^{[12]}$ The nature of saccharides and polysaccharides determined the shape of $\mathrm{ZnO}$ particles (rods, spindles and hollow or compact spheres). ZnO nanoparticles were synthesized by alkali precipitation from a $\mathrm{Zn}\left(\mathrm{NO}_{3}\right)_{2}$ solution containing chitosan. ${ }^{[27]}$

\section{FT-IR Spectra}

The FT-IR spectra of selected $\mathrm{ZnO}$ samples are shown in Figures 5 and 6 . In the spectra of reference samples $Z 1$ to

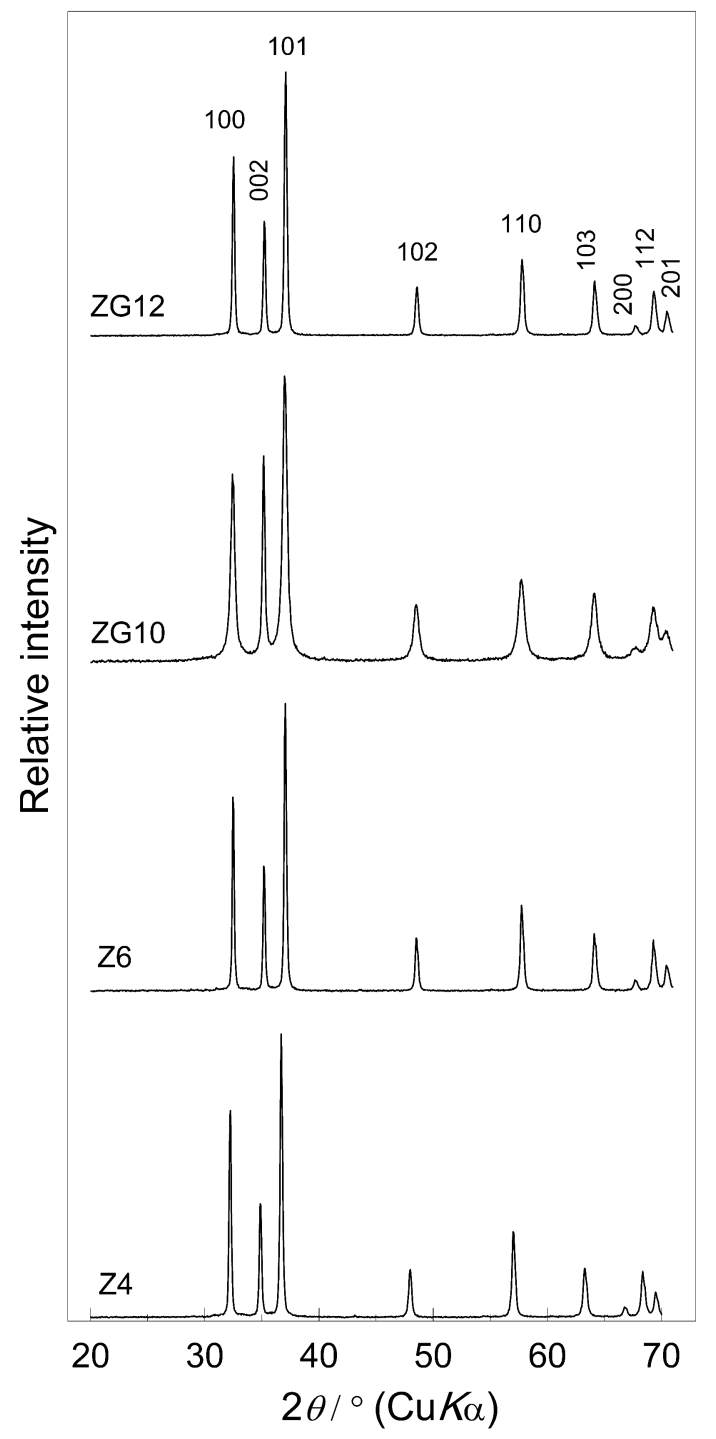

Figure 2. Selected XRD patterns of reference samples Z4, Z6 and samples ZG10, ZG12 precipitated in the presence of gum arabic.

Z3 the broad IR band at 3442 to $3444 \mathrm{~cm}^{-1}$ is due to adsorbed $\mathrm{H}_{2} \mathrm{O}$ molecules, whereas the two IR bands at 546 to 547 and $394 \mathrm{~cm}^{-1}$, respectively, can be assigned to $\mathrm{ZnO}$. The IR spectrum of $\mathrm{ZnO}$ was discussed in reference literature. For example, Hayashi et al. proposed three distinct absorption peaks located between the bulk TOphonon frequency $\left(\omega_{T I I}\right)$ and LO-phonon frequency $\left(\omega_{L} \perp\right)$. [28] The peaks shifted towards lower frequencies when the permittivity of the surrounding medium increased. The $\mathrm{ZnO}$ lattice vibration modes at $300 \mathrm{~K}$ : TO $\left(A_{1}\right)$ at $378 \mathrm{~cm}^{-1}, \mathrm{LO}\left(A_{1}\right)$ at $574 \mathrm{~cm}^{-1}, \mathrm{TO}\left(E_{1}\right)$ at $410 \mathrm{~cm}^{-1}, \mathrm{LO}\left(E_{1}\right)$ at $590 \mathrm{~cm}^{-1}, E_{2}^{\text {high }}$ at $438 \mathrm{~cm}^{-1}$ and $E_{2}^{\text {low }}$ at $99 \mathrm{~cm}^{-1}$ were reported. ${ }^{[29]}$ The polar modes $A_{1}$ and $E_{1}$ are IR and Raman active. Non-polar 
modes $E_{2}$ are only Raman active. The IR spectrum of $\mathrm{ZnO}$ was also investigated by Andrés-Vergés et al. ${ }^{[30,31]}$ These authors showed that the IR spectrum of their $\mathrm{ZnO}$ samples could vary from a broad single band over the doublet up to

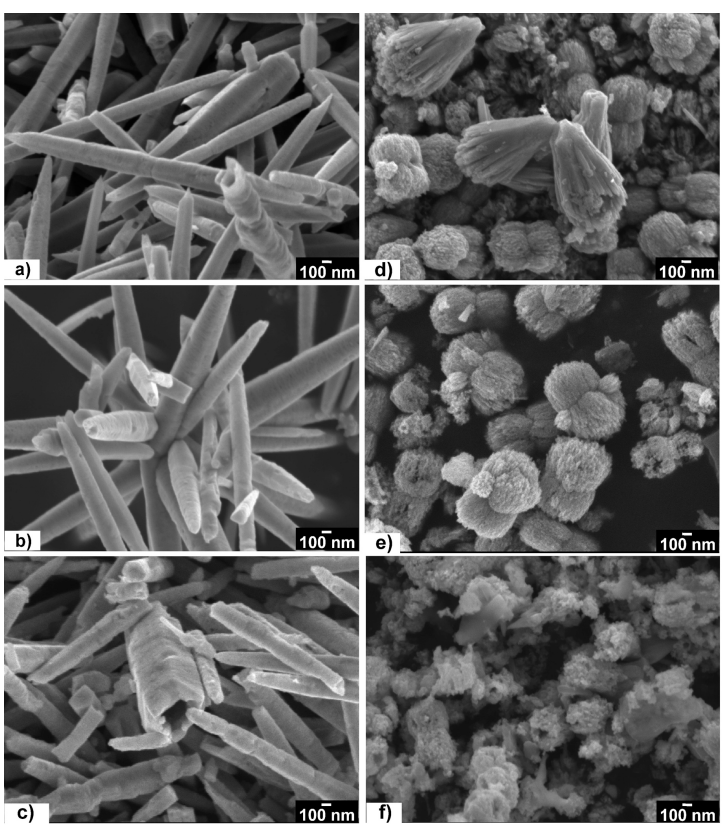

Figure 3. FE-SEM images of samples (a) Z1, (b) Z2, (c) Z3 and the effect of gum arabic addition (samples (d) ZG7, (e) ZG8, (f) ZG9)
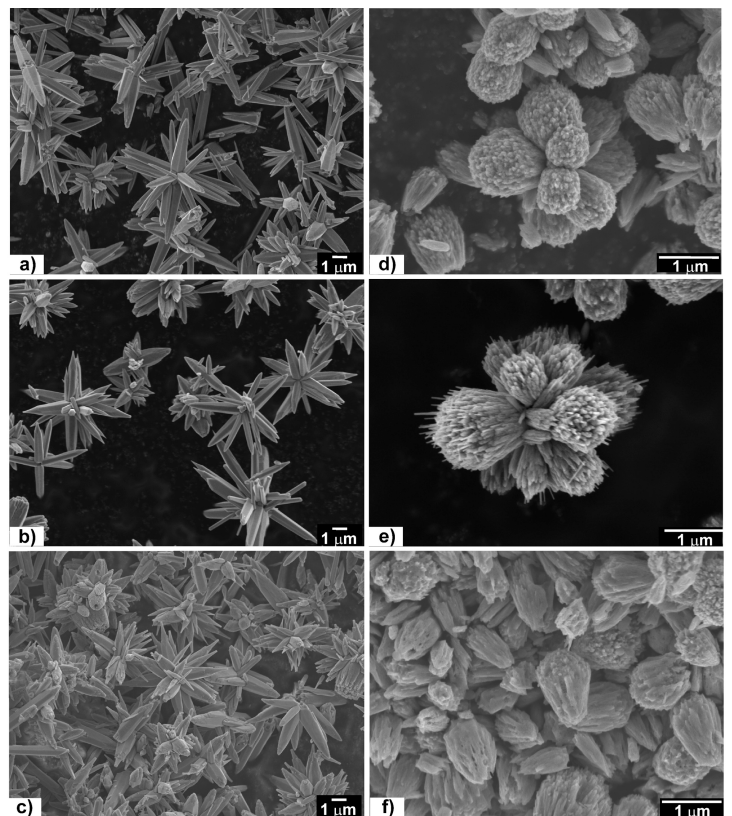

Figure 4. FE-SEM images of reference samples (a) Z4, (b) Z5, (c) Z6 and the effect of gum arabic addition (samples (d) ZG10, (e) ZG11, (f) ZG12). a three band superposition. The origin of a band at $493 \mathrm{~cm}^{-1}$, which sometimes can appear in the IR spectrum of $\mathrm{ZnO}$, was also discussed.

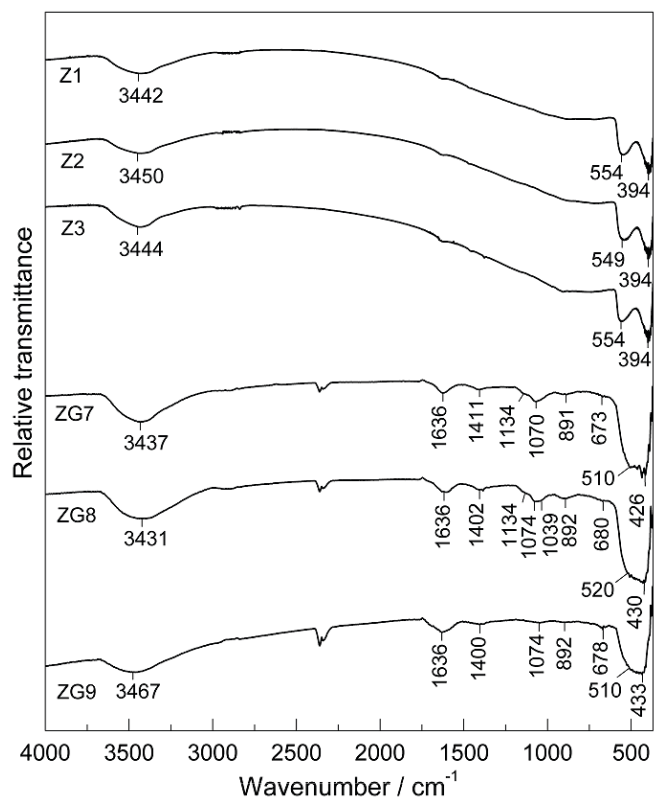

Figure 5. FT-IR spectra of reference samples Z1, Z2, Z3 and those precipitated in the presence of gum arabic (samples ZG7, ZG8, ZG9).

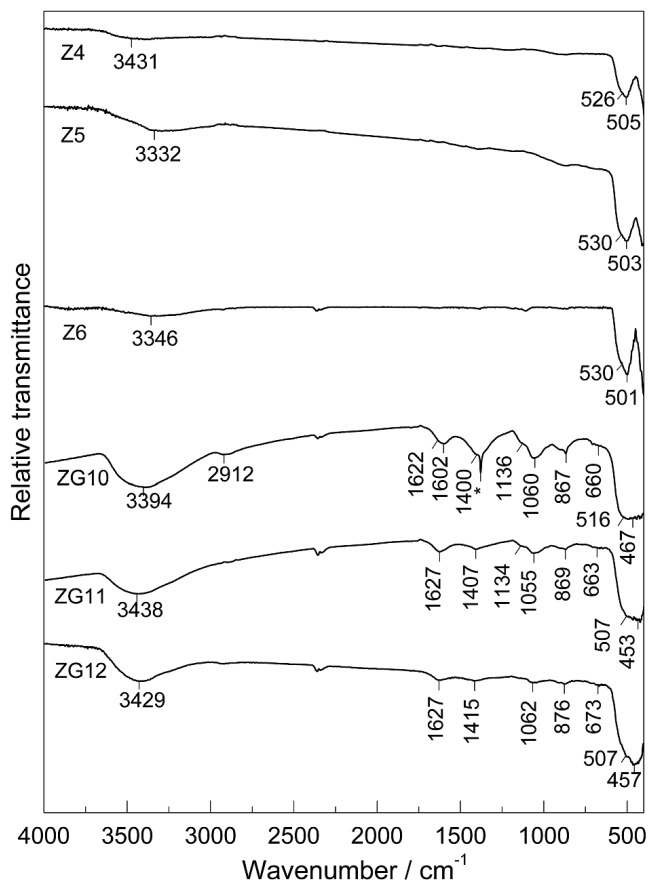

Figure 6. FT-IR spectra of reference samples Z4, Z5, Z6 and those precipitated in the presence of gum arabic (samples ZG10, ZG11, ZG12; * parasitic line). 
The addition of gum arabic to the precipitation system caused a significant change in the shape of the ZnO spectrum (IR spectra ZG7 to ZG9 in Figure 5). The IR bands at 3437 to $3467 \mathrm{~cm}^{-1}$ and $1636 \mathrm{~cm}^{-1}$ are due to $\mathrm{H}_{2} \mathrm{O}$ stretching and bending vibrations, respectively. The origin of these IR bands is related with hygroscopic nature of $\mathrm{ZnO}$. A broad single IR band at 426 to $433 \mathrm{~cm}^{-1}$ was noticed, instead of two well-separated IR bands observed for samples Z1 to Z3. A similar effect was obtained for samples Z4 to Z6 versus samples ZG10 to ZG12, as shown in Figure 6 . This effect can be mainly assigned to a great difference in the shape and size of $\mathrm{ZnO}$ particles (Figures 3 and 4) precipitated in the absence or presence of gum arabic in the precipitation system. The IR spectra of samples ZG7 to ZG9 and ZG10 to ZG12 showed additional IR bands, for example at $673,891,1070,1134$, and 1411 in the spectrum ZG7 which can be assigned to gum arabic in line with the FT-IR spectrum of gum arabic (Figure 7) used in our experiments. The characteristic functional groups of gum arabic are carboxylates, hydroxyls and amines. The assignments of IR bands corresponding to gum arabic are discussed in reference literature. ${ }^{[32-36]}$ The functional groups of gum arabic are responsible for the formation of a corona on the particles consisting of more layers of this biopolymer. The mechanism of the corona formation includes the interactions of gum arabic from nucleation to the crystal growth of particles. From FE-SEM images in Figures 3 and 4 it is well visible that the formation of a gum arabic corona strongly suppressed $\mathrm{ZnO}$ particle growth. From the FT-IR spectra of ZnO samples ZG7 to ZG9 and ZG10 to ZG12 it is visible that the relative intensity of gum arabic bands decreased with the autoclaving time prolonged from 2 to $24 \mathrm{~h}$. This release of gum arabic polymers is actuated by the recrystallization and crystal growth of $\mathrm{ZnO}$ subunits with a prolonged time of autoclaving.

\section{UV/Vis and PL Spectra}

The UV/Vis spectra in the absorption mode of selected samples Z1 to Z3 and ZG7 to ZG9 are shown in Figure 8. The band gap values were calculated using the procedure introduced by Dharma and Pisal[37] and for selected $\mathrm{ZnO}$ samples are given in Table 3. From Table 3 it is visible that the $E$ / eV values are higher for $\mathrm{ZnO}$ samples precipitated in the presence of gum arabic. This can be related to a change in the size of $\mathrm{ZnO}$ nanoparticles (crystallites) formed in the presence of gum arabic.

The PL spectra of selected $\mathrm{ZnO}$ samples are shown in Figures 9 and 10. The spectra of reference samples $Z 1$ and Z3 in Figure 9ab are recorded in powder form, whereas Figure 9cd shows the spectra of the same $\mathrm{ZnO}$ powders dispersed in pure ethanol. The spectrum of samples $Z 1$ shows a series of peaks from $400 \mathrm{~nm}(\sim 3.1 \mathrm{eV})$ to $532 \mathrm{~nm}$ $(\sim 2.33 \mathrm{eV})$. A very strong near band-edge UV emission at $400 \mathrm{~nm}$ can be assigned to the direct recombination of free excitons. ${ }^{[38]}$ The series of peaks in the visible spectral region shown in Figure 9ab is of a very complex nature. Generally, these peaks in the PL spectrum of $\mathrm{ZnO}$ can be considered as different intrinsic defects, such as oxygen vacancies $V_{0}$, zinc

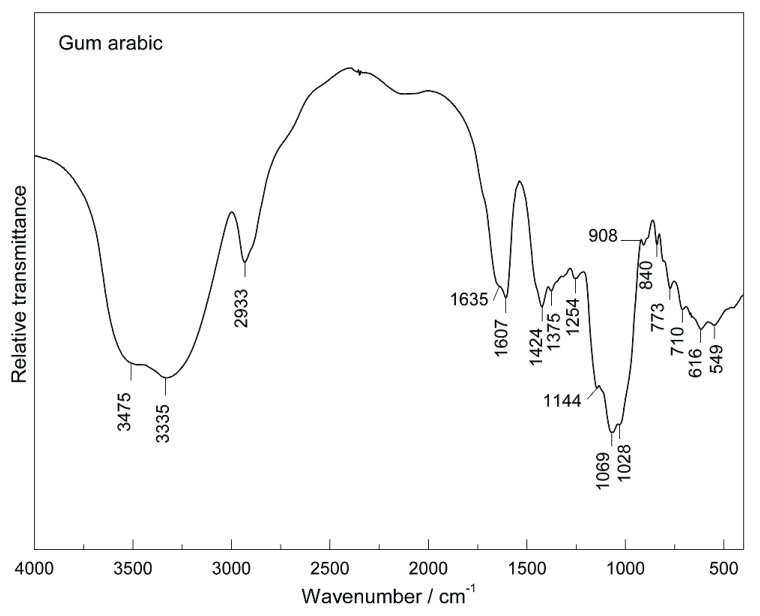

Figure 7. FT-IR spectrum of gum arabic.

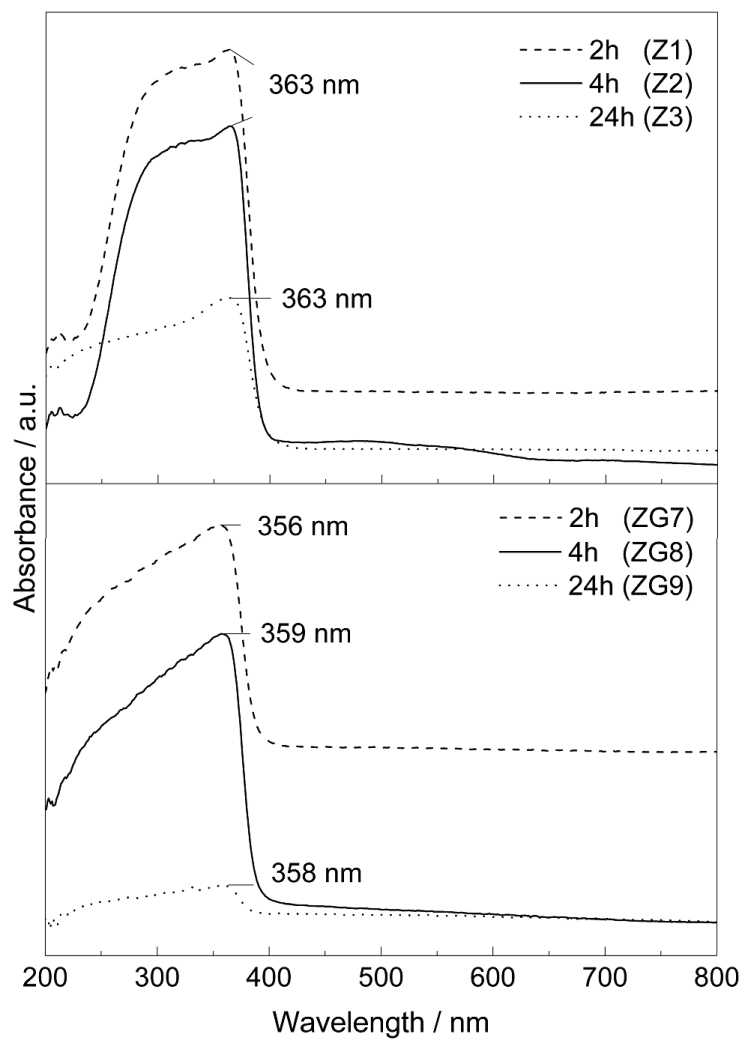

Figure 8. UV/Vis spectra of reference samples Z1, Z2, Z3 and those precipitated in the presence of gum arabic (samples ZG7, ZG8, ZG9). 
vacancies $V_{Z n}$, oxygen interstitials $\mathrm{O}_{\mathrm{i}}$, zinc interstitials $\mathrm{Zn}_{\mathrm{i}}$ and oxygen antisites $\mathrm{O}_{\mathrm{Zn}}$. The appearance of these peaks can vary with the $\mathrm{ZnO}$ nano / microstructure, which is on the other hand strongly dependent on the route and conditions of the $\mathrm{ZnO}$ synthesis. The shoulders at $410 / 420$ $\mathrm{nm}(\sim 3.02 / 3.0 \mathrm{eV})$ in Figure 9a are due to the violet emission. Fan et al. recorded the PL spectrum of a $\mathrm{ZnO}$ film and noticed the violet emission peak between 424 and $413 \mathrm{~nm}(\sim 2.92-3.00 \mathrm{eV}) .{ }^{[39]}$ The violet emission is assigned to the electron transition from the valence band to interstitial zinc $\left(\mathrm{Zn}_{\mathrm{i}}\right)$ level under low-oxygen pressure (50$500 \mathrm{~Pa}$ ). Under high oxygen pressure the characteristic emission at 2.53 to $2.30 \mathrm{eV}$ was noticed. The defect concentration in a Zn-rich zinc oxide is three orders of magnitude greater than that in an O-rich zinc oxide, thus indicating that $V_{O}$ is more readily formed than $V_{z n}$ in the thermochemical treatment of $\mathrm{ZnO}$. Brahma and Shivashankar measured the XPS spectra of ZnO samples and on the basis of these measurements concluded that oxygen vacancies play an important role in the $\mathrm{PL}$ behaviour of $\mathrm{ZnO}$ and that the concentration of $\mathrm{V}_{0}$ could be related to the experimental conditions of $\mathrm{ZnO}$ synthesis. ${ }^{[40]}$ The PL spectrum of reference sample Z3 (Figure 9b) showed almost the same spectral feature as for sample Z1. A small relative intensity and a broad band at 532 / $526 \mathrm{~nm}$ $(\sim 2.33 / 2.36 \mathrm{eV})$ observed for these samples can be related to the green emission.

The PL spectra of $\mathrm{ZnO}$ powders (samples $\mathrm{Z1}$ and $\mathrm{Z3}$ ) dispersed in pure ethanol (Figure 9cd) showed the disappearance of characteristic peaks in the blue emission spectral region. The presence of ethanol produced a „healing"effect on ZnO particles, thus softening intrinsic

Table 3. Band gap values of selected Z and ZG samples.

\begin{tabular}{ccc}
\hline Sample & $\lambda^{\text {(a) }} / \mathrm{nm}$ & $E /$ ev \\
\hline Z1 & 393 & 3.16 \\
Z3 & 395 & 3.14 \\
ZG7 & 391 & 3.17 \\
ZG8 & 387 & 3.20 \\
ZG9 & 388 & 3.19 \\
ZG4 & 385 & 3.22 \\
ZG5 & 406 & 3.05 \\
ZG6 & 402 & 3.08 \\
ZG10 & 397 & 3.12 \\
ZG11 & 396 & 3.13 \\
ZG12 & 393 & 3.16 \\
\hline
\end{tabular}

(a) Intersection between spectrum slope line and base line. surface defects, which less affected the blue emission. It can be supposed that in this process the oxygen atom from $\mathrm{C}_{2} \mathrm{H}_{5} \mathrm{OH}$ played a key role by covering oxygen vacancies $\left(\mathrm{V}_{0}\right)$ on the surface of $\mathrm{ZnO}$ particles. The PL band centred at 548 / $544 \mathrm{~nm}(\sim 2.26 / 2.28 \mathrm{eV})$ can be assigned to the green emission. The nature of green luminescence emission was the subject of discussion in reference literature. ${ }^{[41,42]} \mathrm{The} P \mathrm{PL}$ spectra of reference $\mathrm{ZnO}$ powders $\mathrm{Z4}$ to $\mathrm{Z6}$ and $\mathrm{ZnO}$ powders ZG10 to ZG12, all dispersed in ethanol (Figure 10) showed spectral features very similar to those shown in Figure $9 \mathrm{~cd}$.

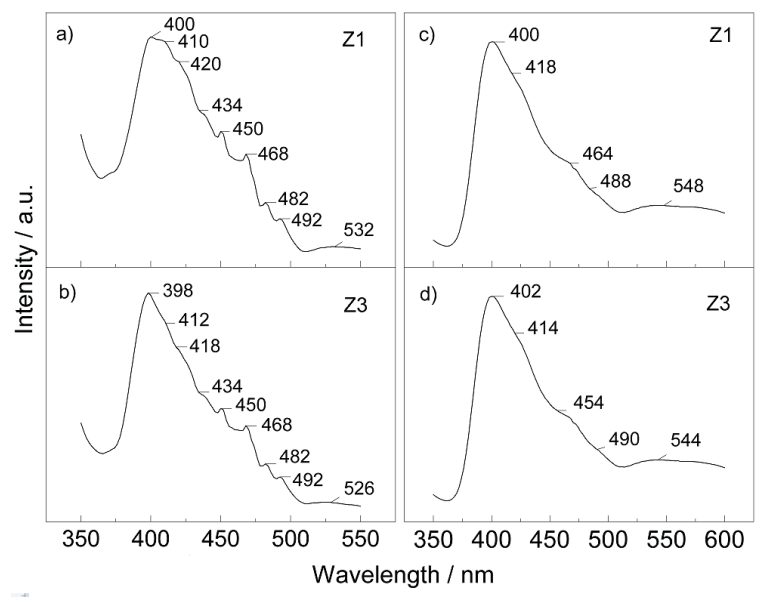

Figure 9. PL spectra of samples in powder form ((a) Z1, (b) Z3) and of the same powders dispersed in pure ethanol ((c) Z1, (d) Z3).

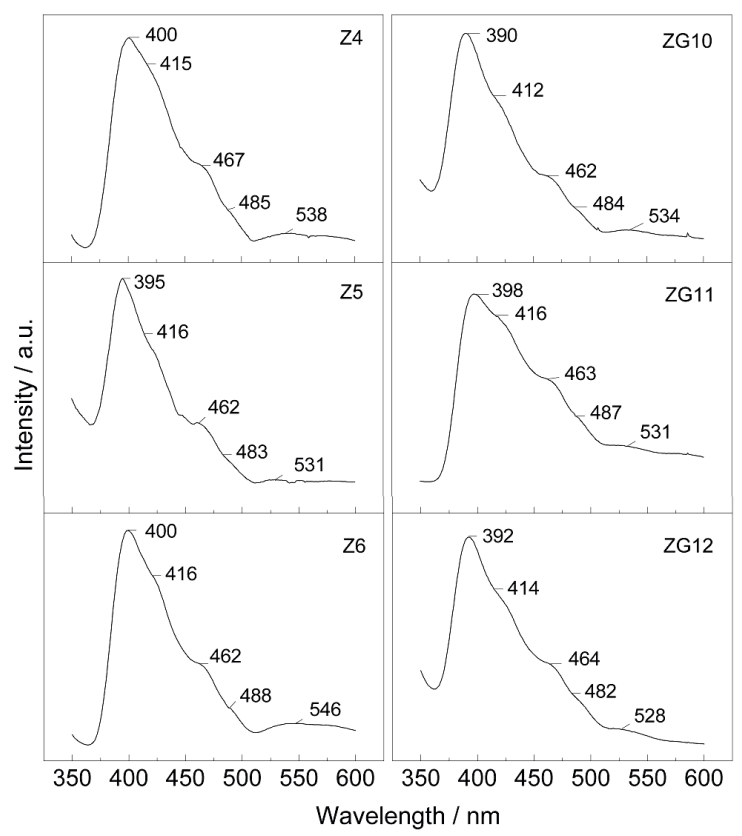

Figure 10. PL spectra of reference samples ( $Z 4$ to $Z 6$ and ZG10 to ZG12) in powder form dispersed in pure ethanol. 


\section{CONCLUSION}

Gum arabic showed a strong effect on the nano / microstructure of $\mathrm{ZnO}$ particles precipitated from zinc acetylacetonate. XRD of all samples corresponded only to the presence of würtzite-type $\mathrm{ZnO}$ crystal structure; however, their nano/microstructures were very different. The hydrothermal treatment of $\mathrm{Zn}(\mathrm{acac})_{2}$ in $\mathrm{H}_{2} \mathrm{O}$ yielded $\mathrm{ZnO}$ rods of micron range length, and some rods were hollow. In the presence of gum arabic $\mathrm{ZnO}$ twin-brushes, consisting of nanoparticles, were noticed. The hydrothermal treatment of zinc acetylacetonate added to an alkaline $\left(\mathrm{NH}_{4} \mathrm{OH}\right)$ aqueous solution yielded $\mathrm{ZnO}$ particles in the form of multipods (stars). With gum arabic added to this precipitation system the particles consisted of laterally arrayed $\mathrm{ZnO}$ nanorods. The size of $\mathrm{ZnO}$ subunits increased with the prolonged time of autoclaving due to recrystallization via the solution.

The variations in the recorded FT-IR spectra are predominantly due to changes in the $\mathrm{ZnO}$ nano / microstructure. The FT-IR spectra of $\mathrm{ZnO}$ particles formed in the presence of gum arabic showed the residual IR bands of gum arabic in spite of subsequent washing of these particles. The corona formation played an important role in the development of the nano / microstructure from nucleation to the final $\mathrm{ZnO}$ product.

UV/Vis spectra recorded for ZnO particles precipitated from $\mathrm{Zn}(\mathrm{acac})_{2}$ in the presence of gum arabic and the $\mathrm{NH}_{4} \mathrm{OH}$ solution showed higher band gap energies than reference samples, which can be related to the decreased size of $\mathrm{ZnO}$ nanocrystallites. The PL spectra of $\mathrm{ZnO}$ powders dispersed in pure ethanol were very similar. It was found that characteristic peaks in the blue emission region recorded for ZnO powders were disappearing. Evidently, the presence of ethanol had a "healing" effect on $\mathrm{ZnO}$ particles, thus softening the intrinsic surface defects responsible for the blue emission. It was suggested that this effect was caused by oxygen atoms in $\mathrm{C}_{2} \mathrm{H}_{5} \mathrm{OH}$ covering oxygen vacancies $\left(\mathrm{V}_{0}\right)$ at the $\mathrm{ZnO} / \mathrm{C}_{2} \mathrm{H}_{5} \mathrm{OH}$ interface.

\section{REFERENCES}

[1] T. Zhang, W. Dong, M. Keeter-Brewer, S. Konar, R. N. Njabon, Z. R. Tian, J. Am. Chem. Soc. 2006, 128, 10960.

[2] S. Cho, J.-W. Jang, S.-H. Jung, B. R. Lee, E. Oh, K.-H. Lee, Langmuir 2009, 25, 3825.

[3] A. Šarić, S. Musić, M. Ivanda, J. Mol. Struct. 2011, 993, 219.

[4] L. Shen, N. Bao, K. Yanagisawa, K. Domen, C. A. Grimes, A. Gupta, J. Phys. Chem. C 2007, 111, 7280.

[5] F. Li, L. Hu, Z. Li, X. Huang, J. Alloys Compd. 2008, 465, L14.
[6] A. P. A Oliveira, J.-F. Hochepied, F. Grillon, M.-H. Berger, Chem. Mater. 2003, 15, 3202.

[7] L.-Z. Zhang, L. Xiang, Res. Chem. Intermed. 2011, 37, 218.

[8] T. T. Ha, T. D. Canh, N. V. Tuyen, ISRN Nanotechnol. 2013.

[9] A. E. Suliman, Y. Tang, Z. Xin, Z. Jia, Asian J. Appl. Sci. 2006, 6, 1298.

[10] D. Tao, W. Qian, Y. Huang, F. Wei, J. Cryst. Growth 2004, 271, 353.

[11] J. Duan, X. Huang, E. Wang, Mater. Lett. 2006, 60, 1918.

[12] A. Stan, C. Munteanu, A. M. Musuc, R. Birjega, R. Ene, A. Ianculescu, I. Raut, L. Jecu, M. B. Doni, E. M. Anghel, O. Carp, Dalton Trans. 2015, 44, 7844.

[13] Y. Gan, F. Gu, D. Han, Z. Wang, G. Guo, J. Nanomater. 2010.

[14] Y.-H. Tseng, M.-H. Liu, Y.-W. Kuo, P. Chen, C.-T. Chen, Y.-F. Chen, C.-Y. Mou, Chem. Commun. 2012, 48, 3215.

[15] O. Carp, A. Tirsoaga, B. Jurca, R. Ene, S. Somacescu, A. Ianculescu, Carbohydr. Polym. 2015, 115, 285.

[16] M. Jitianu, D. V. Goia, J. Colloid Interface Sci. 2007, 309, 78.

[17] M.-H. Liu, Y.-H. Tseng, H. F. Greer, W. Zhou, C.-Y. Mou, Chem. - A European Journal 2012, 18, 16104.

[18] J-K. Yan, Y-Y. Wang, L. Zhu, J-Y. Wu, RCS Adv, 2016, 6, 77752.

[19] Ž. Petrović, M. Ristić, S. Musić, J. Alloys Compd. 2017, 694, 1331.

[20] S. Musić, A. Šarić, Ceram. Int. 2012, 38, 6047.

[21] Y. Inubushi, R. Takami, M. Iwasaki, H. Tada, S. Ito, J. Colloid Interface Sci. 1998, 200, 220.

[22] S. Brahma, K. J. Rao, S. Shivashankar, Bull. Mater. Sci. 2010, 333, 89.

[23] G. Ambrožič, S. D. Škapin, M. Žigon, Z. Crnjak-Orel, J. Colloid Interface Sci. 2010, 346, 317.

[24] A. Phuruangrat, T. Thongtem, S. Thongtem, Ceram. Int. 2014, 40, 9069.

[25] Y.-H. Tseng, H.-Y. Lin, M.-H. Liu, Y.-F. Chen, C.-Y. Mou, J. Phys. Chem. C 2009, 113, 18053.

[26] H. F. Greer, W. Zhou, M.-H. Liu, Y.-H. Tseng, C.-Y. Mou, CrystEngComm 2012, 14, 1247.

[27] M. Thirumavalavan, K.-L. Huang, J.-F. Lee, Materials 2013, 6, 4198.

[28] S. Hayashi, N. Nakamori, H. Kanamori, Y. Yodogawa, K. Yamamoto, Surf. Sci. 1979, 86, 665.

[29] B. K. Meyer, H. Alves, D. M. Hofmann, W. Kriegseis, D. Forster, F. Bertram, J. Christen, A. Hoffmann, M. Strassburg, M. Dworzak, U. Haboeck, A. V. Rodina, Phys. Status Solidi B 2004, 241, 231.

[30] M. Andrés-Vergés, C. J. Serna, J. Mater. Sci. Lett. 1988, 7, 970. 
[31] M. Andrés-Vergés, A. Mifsud, C. J. Serna, J. Chem. Soc. Faraday Trans. 1990, 86, 959.

[32] A. C. A Roque, A. Bicho, I. L. Batalha, A. S. Cardoso, A. Hussain, J. Biotechnol. 2009, 144, 313.

[33] P. Vanloot, N. Dupuy, M. Guiliano, J. Artaud, Food Chem. 2012, 135, 2554.

[34] C.-C. Wu, D.-H. Chen, Gold Bull. 2010, 43, 234.

[35] Y. N. Rao, D. Banerjee, A. Datta, S. K. Das, R. Guin, A. Saha, Radiat. Phys. Chem. 2010, 79, 1240.

[36] S. S. Banerjee, D.-H. Chen, J. Hazard Mater. 2007, 147, 792.

[37] J. Dharma, A. Pisal, Simple method of measuring the band gap energy value of $\mathrm{TiO}_{2}$ in the powder form using UV/Vis/NIR spectrometer, Application Note 935, Perkin- Elmer Inc., Shelton, CT., USA, 2009, pp. 1-4.

[38] S. K. Mishra, R. K. Srivastava, S. G. Prakash, R. S. Yadav, A. C. Pandey, Opto-Electron. Rev. 2010, 18, 467.

[39] X. M. Fan, J. S. Lian, L. Zhao, Y. H. Liu, Appl. Surf. Sci. 2005, 252, 420.

[40] S. Brahma, S. A. Shivashankar, J. Alloys Compd. 2014, 854, 331.

[41] S. C. Lyu, Y. Zhang, H. Ruh, H.-J. Lee, H.-W. Shim, E. K. Suh, C. J. Lee, Chem. Phys. Lett. 2002, 363, 134.

[42] P. A. Rodnyi, I. V. Khodyuk, Opt. Spectrosc. 2011, 111, 776. 